Collaboration, Interdisciplinarity, and the Epistemology of Contemporary Science

Andersen, Hanne

Published in:

Studies in History and Philosophy of Science Part A

DOI:

10.1016/j.shpsa.2015.10.006

Publication date:

2016

Document version

Early version, also known as pre-print

Citation for published version (APA):

Andersen, H. (2016). Collaboration, Interdisciplinarity, and the Epistemology of Contemporary Science. Studies in History and Philosophy of Science Part A, 56, 1-10. https://doi.org/10.1016/j.shpsa.2015.10.006 


\title{
COLLABORATION, INTERDISCIPLINARITY, AND THE EPISTEMOLOGY OF CONTEMPORARY SCIENCE
}

\author{
Hanne Andersen, Department of Science Education, Øster Voldgade 3, DK-1350 Copenhagen K \\ Forthcoming in Studies in History and Philosophy of Science, A
}

\begin{abstract}
Over the last decades, science has grown increasingly collaborative and interdisciplinary and has come to depart in important ways from the classical analyses of the development of science that were developed by historically inclined philosophers of science half a century ago. In this paper, I shall provide a new account of the structure and development of contemporary science based on analyses of, first, cognitive resources and their relations to domains, and second of the distribution of cognitive resources among collaborators and the epistemic dependence that this distribution implies. On this background I shall describe different ideal types of research activities and analyze how they differ. Finally, analyzing values that drive science towards different kinds of research activities, I shall sketch the main mechanisms underlying the perceived tension between disciplines and interdisciplinarity and argue for a redefinition of accountability and quality control for interdisciplinary and collaborative science.
\end{abstract}

Over the last century, science has grown increasingly collaborative, and most scientific knowledge today is produced by groups in which multiple scientists collaborate in order to combine their knowledge, manpower, materials and other resources (Wuchty, Jones, \& Uzzi, 2007). Further, much scientific research today cut across disciplinary boundaries (Braun \& Schubert, 2003; Porter \& Rafols, 2009). But at the same time, there is an ever ongoing specialization in which new scientific specialties and disciplines continuously proliferate (Stichweh, 1992; 2010).

It is often argued that these developments are all tightly knit to the continued growth of the scientific enterprise, both with respect to the issues addressed and the volume of the activities addressing them. Thus, it has been a recurrent argument in reports from research policy and funding organizations at least since the 1960 es that, as science move to more and more complex and demanding problems, it requires collaborations both within and across disciplines. At the same time it is also argued that as science moves towards grasping the world in ever more detail, the individual scientist needs to specialize more and more in order to master the increasingly specialized tools and to be in command of an ever growing literature. This has resulted in paradoxical situation that while interdisciplinarity is continuously proclaimed and demanded, at the same time scientists also continue to specialize (Weingart, 2000). 
In this paper, I shall address these developments in contemporary science and lay the foundations for a philosophical analysis of the structure and development contemporary science. One the one hand, this analysis is a return to the structure of science and its development as a central topic for general philosophy of science; a topic that has been dormant in recent decades while interest of philosophers turned to the differences between disciplines, historical periods, and the many individual elements of the scientific enterprise. On the other hand, what I propose is an analysis of the development of science that it informed by the attention to details and differences that has been prominent since the generalized accounts of the 1960es and 1970es.

The account takes the structure of research activities as its central focus. Based on analyses of the cognitive resources employed in individual research activities it is examined how they relate to domains in a historical process, and how their distribution among the researchers involved gives rise to relations of epistemic dependence. For the sake of analytical clarity I shall first examine how the cognitive resources employed in a research activity relate to domains and how to understand the individual's expertise on such a picture. Next, I shall examine the epistemic dependence between scientists, and combining the analyses of cognitive resources and epistemic dependence I shall provide a renewed view of how to understand disciplines and specialties in terms of different ideal types of research activities in a two-dimensional spectrum. Finally, analyzing values that drive science in various directions I shall sketch the main mechanisms underlying the perceived tension between disciplines and interdisciplinarity and argue for a redefinition of accountability and quality control for interdisciplinary and collaborative science.

\section{PHILOSOPHICAL ACCOUNTS OF DISCIPLINARY DEVELOPMENTS - AND}

\section{BEYOND}

The development of disciplines or specialties, as well as their subdivision into fields or domains, was a major topic of interest within the historically inclined philosophy of science that flourished from the 1960es some decades onwards. Philosophers of science such as Kuhn, Lakatos, Laudan, Toulmin, and Shapere described the development of science by focusing on the development of individual areas of science, and the development of these areas were then described in terms of, for example, paradigminduced normal science and paradigm changing revolutions (Kuhn, 1970), progressing and degenerating research programs (Lakatos, 1971), successive research traditions (Laudan, 1977), or domains connected through history by chains-of-reasoning (Shapere, 1977). On these traditional accounts of how individual areas within science developed over time, a scientific discipline (or specialty, field or domain) could be understood at the same time as an epistemic unit consisting of a 
set of closely related cognitive resources such as, for example, concepts, models and theories, and as a social unit consisting of highly similar experts who were employing and at the same time developing their shared cognitive resources.

The most detailed attempt at describing the relation between the cognitive and social aspects of a given area of science could be found in Kuhn's account of normal science. On Kuhn's account, scientists within a given specialty have been through substantially the same kind of training, and through this training they have required very similar and strong mental sets; what Kuhn referred to first as a paradigm and later as a disciplinary matrix. On this analysis, the mastery of the disciplinary matrix in the form of concepts, generalization, values and exemplars, as well as the ability to apply it to recognize, define and creatively solve new research puzzles were seen as the core elements of the expertise that enabled the individual practitioners of a given specialty to contribute to its development. Further, by drawing on this disciplinary matrix that they all shared, each of the practitioners in the specialty could be seen as epistemically autonomous agents who were each able in similar ways to recognize the same, potential new research puzzles that could be solved in ways similar to previously recognized puzzles.

Such an account implied that as a social unit, a specialty or discipline was a community of scientists with highly similar expertise based on their possessing more or less the same set of cognitive resources that enabled them to identify more or less the same problems and methods for their solution. Conversely, as an epistemic unit, a specialty or discipline was a set of cognitive resources that were transferred historically from one generation to the next through a particular form of rigorous training. A specialty or discipline was therefore characterized by a close, bipartite relation between the scientific community and the cognitive resources that members of this community employed, while the individual scientists and the activities that they engaged in could be seen as tokens of the types of similar community members working on similar problems. On this model, to the extent that there were differences in the cognitive resources between different scientists, these were primarily seen as a latent reservoir that only in a phase of crisis would become manifest as different responses to anomalies and thereby serve as a mechanism for risk spreading during the development of alternative paradigms and an eventual paradigm shift.

It also follows from such an account that, due to their highly similar contributory expertise, ${ }^{1}$ members of the community would be epistemically autonomous agents largely agreeing on what to perceive as

${ }^{1}$ The notion of contributory expertise has originally been advanced by Collins and collaborators (Collins \& Evans, 2002) as the ability to contribute to the domain's development, but without specifying the various components of this ability. See Goddiksen (2014) for a more detailed specification based on a criticism of Collin's 
research questions and what to accept as solutions. Hence, although individual scientists as epistemically autonomous agents could compete on priority in solving some given research problem, they would all have the same ability to recognize the problems and appreciate their solution. By the same token, they would also each have the same ability to detect shortcomings of proposed solutions and provide improvements. Although this was rarely addressed explicitly in the accounts advanced by Kuhn and others, quality control based on the critical scrutiny of new results by epistemic autonomous peers could therefore be seen as firmly embedded in the disciplinary community. Hence, the beauty of this close, bipartite relation between epistemic resources and the community of scientists employing these resources was how it tied together expertise, education, and quality control.

At the same time, the fundamental challenge for this account based on a bipartite relation between a community and its cognitive resources is how to avoid the circularity that "[a] paradigm is what the members of a scientific community share, and conversely a scientific community consists of men who share a paradigm" (Kuhn, 1970, p. 1976). Kuhn argued in the 1970 Postscript that for the analyst, this circularity could be broken by isolating the scientific community first and then the corresponding paradigms could be discovered by scrutinizing the behavior of the communities' members. For the "empirical techniques" required for the exploration of community structures, Kuhn referred to the then emerging sociological literature on communication patterns and invisible colleges as advanced by, among others, Hagstrom (1965), Price (Price \& Beaver, 1966) and Crane (1969). However, as this research developed over the following decades it became clear that it did not offer the clear and unequivocal identification of specialties or disciplines that Kuhn had anticipated. Instead, it revealed a multitude of criss-crossing relations established by the multitude of individual scientists whom Kuhn had reduced to more or less identical tokens of the type of community members in his focus on the close, bipartite relation between a community and its shared cognitive resources.

There are several reasons why we cannot identify a unique structural level at which the relation between scientific community and cognitive resources can be unequivocally defined. First, whereas scientists within a given scientific field may share a core set of well-established cognitive resources, at the same time it is the aim of science to continuously develop these cognitive resources, and during this process of science-in-the-making only a few scientists within a given field may be sharing the new cognitive resources being developed to supplement the resources already possessed within the field. Second, scientists usually subspecialize, and members of a profession will therefore share some core parts of a set of cognitive resources while other parts will be shared only by a few. Third, the classical philosophical analyses of the development of science that described the cognitive development of

work. 
individual disciplines or specialties largely ignored scientific activities that cut across disciplinary boundaries and in doing so connects multiple sets of cognitive resources.

As a consequence, instead of focusing on the bipartite relation between the cognitive resources and the social community in which they are shared, while reducing the individual scientists and the activities that they engage in to tokens of disciplinary types, the analysis presented here turns the picture upside down and focuses instead on the individual research activity as it is spanned by the dimensions of cognitive resources and epistemic relations between the scientists employing them. On this background, the analysis presents a continuous and two-dimensional spectrum of research activities from which four ideal types can be described. Further, the analysis reveals important epistemic forces that underlie current developmental patterns in contemporary science and indicates how the tension between disciplinary and interdisciplinary developments can be resolved. ${ }^{2}$

\section{COGNITIVE CONVERGENCE OR DIVERGENCE}

What we have learned from previous decades of work in philosophy and sociology of science is that a scientific domain and the cognitive resources employed within it are inherently dynamic entities that are continuously developing. Hence, in the absence of fixed boundaries, what identifies the cognitive resources of a domain is their trajectory through history as they both develop and are transferred to new generations of experts.

This historical trajectory is also the back-bone from which the training of a new generation draws its material: exemplary problems in the domain as considered from its contemporary stand and accounts of how they have been solved. During their training, novices are required again and again to study concrete problem solutions and to solve series of closely related problems for themselves. Through this training they gradually develop the ability to classify new problems as instances of known types and to recognize and employ the cognitive resources adequate for solving them (Andersen, 2000). The

\footnotetext{
${ }^{2}$ By focusing on this spectrum of research activities, the analyses offered here has a different focus from recent accounts of the character of contemporary science such as, e.g. the post-normal science account offered by Funcovich and Ravetz $(1993 ; 1995)$ that focuses on the uncertainty implied in research on complex phenomena, or the triple-helix account offered by Etzkowich (2008; Etzkowitz \& Leydesdorff, 2000) that focuses on relations between knowledge producing institutions. It also differs from the mode 1/mode 2 account offered by Nowotny and collaborators (Gibbons et al., 1994; Nowotny, Scott, \& Gibbons, 2001) that focuses on temporary and transdisciplinary collaborations carried out in a context of application, but does neither consider the spectrum ranging from the disciplinary to the transdisciplinary activities, nor the epistemic dependence relations between the involved researchers as this account does.
} 
ability to recognize problems belonging to a domain and using the domain's cognitive resources to solve them in a way that will be recognized and accepted by other practitioners using the same resources to solve other domain-relevant problems is one of the core preconditions for the expertise required to contribute to the domain's further development. Traditional disciplinary degree programs usually train novices in a series of basic domains as a precondition for later developing contributory expertise in some subspecialty of the discipline. Later in their training, as the novices specialize and gradually become experts, they will be trained in more specialized domains, and as specialization increases, more emphasis will be on applying the newly mastered cognitive resources to genuinely new situations and to investigate their limits and how to transgress these same limits.

However, scientific research activities in contemporary science are not necessarily confined to a single domain. ${ }^{3}$ Instead, contemporary scientific research activities may be cognitively convergent in the sense that they draw on a set of cognitive resources drawn from a particular domain, or they may be cognitively divergent in the sense that they draw on a combination of cognitive resources drawn from different domains. This is not a distinction in kind, but rather the two ends on a continuum such that any given scientific activity can be more or less cognitively convergent or cognitively divergent.

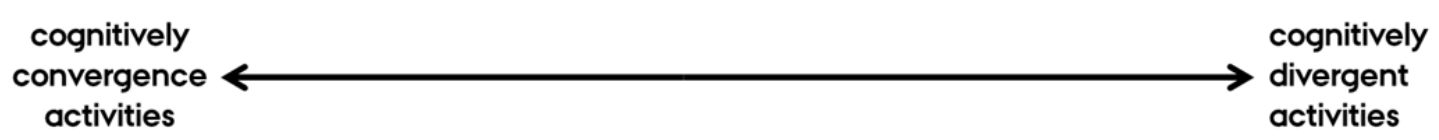

Figure 1. A one-dimensional cognitive spectrum of research activities.

This can be illustrated by a one-dimensional spectrum where activities within research fields such as, for example, quantum field theory or analytic inorganic chemistry will be found in the end of the spectrum that is characterized by cognitive convergence. Scientific research activity in one of these fields usually draws on a relatively uniform set of cognitive resources developed within domains belonging to the field itself. By the same token, scientists in the field have typically developed convergent contributory expertise by having been through more or less similar training and a subsequent life in the profession of the field so that there is be a high degree of overlap in, for example, their ontological beliefs, and the concepts, models, generalizations and methods that they draw on, although through their subspecialization they may each also have developed mastery of additional, highly specialized cognitive resources which their collaborators have not. In this sense, their contributory expertise is convergent, but not fully identical.

\footnotetext{
${ }^{3}$ This should not be read as a claim that previous research activities were confined to single domains. It is the aim of this paper to investigate the current spectrum, not to give an historical account of its historical development.
} 
In the other end of the spectrum, characterized by cognitive divergence, are scientific activities within research fields such as, for example, nanoscale drug delivery, geomicrobiology or integrative neuroscience that each draw on several very different domains. Scientists in these research fields will often have been trained in different disciplines consisting of each their set of different domains, and they will therefore have very divergent contributory expertise. In principle, a single researcher may acquire mastery of cognitive resources from domains from multiple disciplines, for example through training for multiple degrees or through long-term collaborations with collaborators from multiple disciplines. But often, research in such research fields will be carried out by collaborations in which the contributory expertise is distributed among the individual scientists participating in the research activity. Due to their different training they will draw on different sets of cognitive resources and there will be less overlap in their ontological beliefs and in the concepts, generalizations and methods that they draw on and values that they subscribe to. Their contributory expertise can therefore be described as divergent, but not completely disjunct.

Whether such contributions that cut across disciplines are provided by individuals or by collaborations, the cognitive resources from the involved domains need to interlock, that is, there needs to be some connection between, for example, selected concepts, models or generalizations. This interlocking requires that scientists have some additional skills beyond their contributory expertise; skills that enable them to recognize enough of the key elements from another domain to participate in the interlocking process. Usually, recognizing such key elements requires that they have acquired some basic elements of the cognitive resources within this other domain, such as some basic recognition of important ontological categories and some basic understanding of key concepts (Petrie, 1976). ${ }^{4}$ This is the core element of the interlocking expertise that enables scientists in a cognitively divergent research field to interlock their own contributions with contributions from their collaborators who draw on different sets of cognitive resources. ${ }^{5}$ The interplay between contributory

\footnotetext{
${ }^{4}$ Although this point bears resemblance to Galison's (1997) idea of special 'pidgin' languages used in a trading zone, the analysis provided here differs from Galison's by not assuming a relation of incommensurability between different fields.

${ }^{5}$ Collins and Evans (2002) have introduced the notion of 'interactional expertise' to denote the kind of expertise that is required to "interact interestingly with participants" (p. 254). In contrast to the contributory expertise that enables a scientist to contribute to the development within a field, interactional expertise enables interaction, typically in the form of communication, but not active, contributory participation in research activities that lead to new scientific contributions. Collins and Evans have not provided much detail on this kind of expertise beyond the vague description of the ability to interact "interestingly". For a criticism, see Goddiksen (2014) as well as Plaisance \& Kennedy (2014). Further, much of their work has been directed at describing
} 
and interlocking expertise is thus an important aspect of collaborative scientific research activities in cognitively divergent areas, but an aspect that has previously been largely ignored when describing scientific knowledge production from a primarily disciplinary perspective.

\section{FRACTAL AND CRISSCROSSING DOMAIN STRUCTURES}

To exemplify the analysis described above, consider the domain structure of a traditional discipline such as physics. In physics, members of the profession have usually been through similar training at some basic level and they therefore share a fair amount of cognitive resources obtained through this basic training, including the domains of mechanics, thermodynamics, statistical physics, electromagnetism, optics, and some basic relativity theory and quantum physics. These are wellestablished and quite stable domains for which a core of cognitive resources displays very little change, if any at all. Hence, although a new generation of practitioners will follow different paths in their later research career, they can rely on the stability of these core domains to provide stable bridging between the developing domains in which they are engaged.

At later stages of their training, members of the profession gradually specialize differently, and whereas physicists in general may share some basic cognitive resources on, for example, the electrical and thermal properties of solids and liquids, only some have specialized deeper into condensed matter physics to engage with these topics in detail, and they again have subspecialized into many different subfields that at the same time may have a variety of overlaps between them. Hence, there will be different degrees of overlap between individual physicists' contributory expertise. A high degree of overlap will be found in a group of condensed matter physicists working on, for example, defects in semi-conductors, less overlap when comparing to another group of condensed matter physicists working on surface catalysis, and lesser yet when comparing to a group of, say, high energy physicists. Still, due to their similar basic training, there will be by far much more overlap in contributory expertise for scientists from all these various groups of physicists than when comparing to the contributory expertise of, for example, chemists or biologist in general. At the same time, although physicists may share a large amount of cognitive resources developed during their early training in the

interactional expertise as the expertise required of a scholar in science studies in order to interact with scientists for the purpose of performing case studies, while ignoring the issue of how interactional expertise in different domains of science can combine with contributory expertise in the production of new research contributions within the sciences themselves. In contrast, the notion of interlocking expertise introduced here is chosen to focus explicitly on the process of interlocking partial contributions from different areas of expertise in the production of a genuine research contribution in a cognitively divergent research field. At the same time, it is neutral to the question of whether 'integration' is part of the process and thereby also neutral to the standard distinction between inter- and multidisciplinarity. 
profession, not all of these resources may form an equally active part in their contributory expertise as they develop science through their much more narrowly defined scientific research activities at its frontier. Instead, as they specialize into specialties and subspecialties, the cognitive resources that they draw on in the creative development of new, additional resources may often be highly specialized and shared by only few. In this way, domains can be said to have a fractal structure (cf. Abbott, 2001).

At the same time, there are also crisscrossing relations between domains. In a group of, for example, highly specialized condensed matter physicists, the participating scientists may have different contributory expertise at some very advanced and detailed level, but at the same time, due to their similar training not only in the basic areas of physics but also more specialized in condensed matter physics, they have very rich resources available to interlock their individual contributions, even when their contributory expertise differ. Because cognitive resources are widely shared, even on an advanced level, only very little (if any) simplification is needed in the interlocking process. In contrast, in an interdisciplinary group, for example a group of physicists and chemists investigating colloidal nanocrystals, there is less overlap between their contributory expertise and more interlocking expertise is needed in order to interlock their individual contributions to the collaboration.

Acquisition of the basic elements of the cognitive resources from another domain required for interlocking expertise implies some degree of simplification. This simplification has an important implication: When mastering only some simplified form of the cognitive resources of some domain, scientist in need of them will have to defer to experts mastering the full details. Collaborative interlocking therefore typically also involve an element of epistemic dependence.

\section{EPISTEMIC DEPENDENCE OR INDEPENDENCE}

As described above, much contemporary research in cognitively divergent fields takes place in collaborations in which collaborators with different areas of contributory expertise combine their cognitive resources. ${ }^{6}$ When researchers collaborate in this way they typically each provide partial contributions from within their own area of expertise and in other areas defer to their collaborators

\footnotetext{
${ }^{6}$ There is a rich literature in sociology of science as well as in organizational science and in team science research on the organization of collaboration, including analyses of their various organizational formats (e.g. Shrum, Chompalov, \& Genuth, 2001; Shrum, Genuth, \& Chompalov, 2007), their formation (e.g. Genuth, Chompalov, \& Shrum, 2000) and productivity (e.g. Lee \& Bozeman, 2012), the role of emotions in collaborations (Parker \& Hackett, 20201), or inherent tensions in collaborative research (e.g. Hackett, 2005). However, the focus in this paper is solely on the relations of epistemic dependence between collaborators, while room is left for including an additional third dimension to the spectrum of research activities representing power relations.
} 
(Andersen \& Wagenknecht, 2013). But also collaboration between researchers with highly similar contributory expertise may build on a division of labor that makes collaborators epistemically dependent, for example if they divide a large amount of similar tasks among them. ${ }^{7}$ In contrast to these scientific research activities characterized by some degree of epistemic dependence, other scientific research activities also exist in which scientists are not epistemically dependent, for example if they work alone, or if they insist on meticulously checking every detail for themselves rather than deferring to a collaborator. Hence, in addition to the dimension of cognitive divergence or convergence, another important dimension of scientific research activities is the dimension of epistemic dependence or independence between the scientists engaged in the activity. Again, this distinction is not a distinction in kind, but rather two ends on a continuum, such that any given scientific research activity can be characterized by more or less epistemic (in)dependence among the participants in the activity.

epistemic independence between participants

epistemic dependence between participants

Figure 2. A one-dimensional epistemic dependence spectrum of research activities.

The qualification should be noted here that the idea of a scientist engaging in a scientific research activity as fully epistemically independent is a chimera. Modern knowers are never completely epistemically independent and autonomous, not even in their field of specialization. In any scientific field, participants necessarily stand on the shoulders of their predecessors. However, for the sake of analysis I shall for the time being follow Goldberg (2011) in distinguishing between direct epistemic dependence on another individual and diffuse epistemic dependence on a community. Given this distinction, I shall here bracket scientists' epistemic dependence on the community of predecessors for knowledge that has been so widely shared through a long historical process that the original act of deference has vanished from sight. Instead, I shall focus on epistemic dependence on direct collaborators for their contributions to current, collaborative scientific research activities. Hence, while acknowledging that epistemic dependence on previous generations of scientists pervades all of

\footnotetext{
${ }^{7}$ Similar to this distinction between collaborations among scientists with different contributory expertise and scientists with similar contributory expertise, Thagard has introduced a distinction between peer-similar collaborations in which collaborators have substantially the same training, knowledge and skills, and peerdifferent collaborations where collaborators have different training, knowledge and skills (Thagard, 1997; 2006). Thagard also introduces two additional categories: employer/employee and teacher/apprentice collaborations. However, focus in this paper will be on the distribution of expertise among scientists regardless of their power relations.
} 
science and remains its inevitable basis, what is specifically at issue here is the epistemic dependence that holds between scientists engaged in ongoing scientific research activities as part of science-in-themaking. In the final section of the paper I shall return to the implications of adopting the chimerical ideal of the autonomous knower.

\section{THE SPECTRUM OF CONTEMPORARY RESEARCH ACTIVITIES}

The distinction between the dimensions of cognitive divergence or convergence and of epistemic dependence or independence enables a fine-grained analysis of different ideal types of scientific research activities and their characteristics. Importantly, cognitive divergence or convergence and epistemic dependence or independence need to be treated as different dimensions. Although scientists engaging in a cognitively divergent research activity will often be epistemically dependent, they need not be so. Instead, multiple-trained scholars may be capable of engaging in a scientific research activity that cuts across domains from multiple disciplines without having to defer to the expertise of collaborators. Similarly, although scientists engaged in a cognitively convergent scientific research activity will often have similar contributory expertise and will therefore be capable of working more or less independently of each other, they need not do so. Instead, as described above, collaborators with convergent contributory expertise may be epistemically dependent because they have divided a massive amount of similar labor among them which it would be much too time consuming for any of them to repeat. The combination of the dimension of cognitive convergence and divergence and the dimension of epistemic dependence and independence therefore yields a two-dimensional spectrum of scientific research activities that include both disciplinary and interdisciplinary division of labor, and independent and autonomous agents in both disciplinary and interdisciplinary research. 


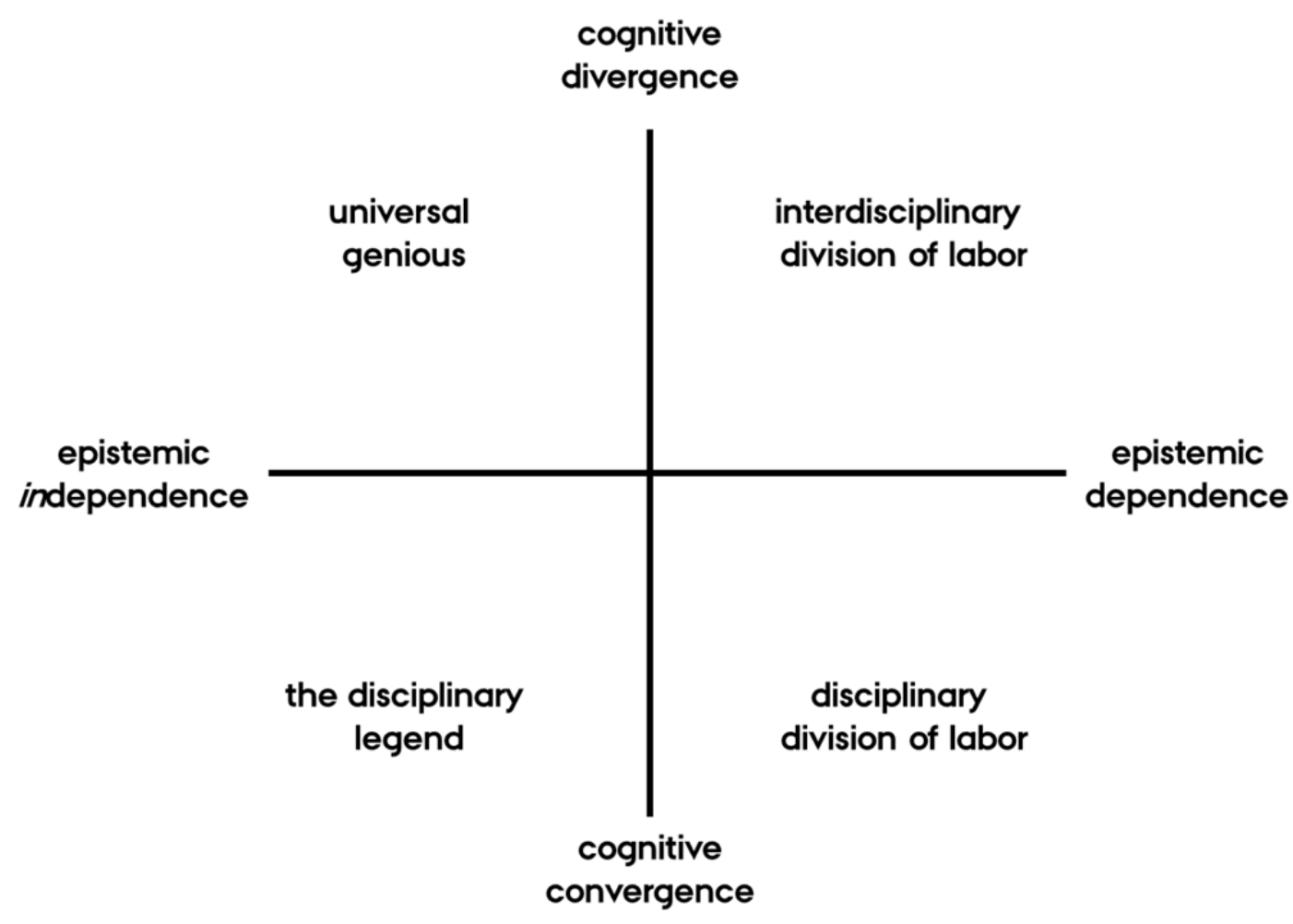

Figure 3. The two-dimensional spectrum of scientific research activities with four different ideal types of scientific research activities.

In the following, I shall first provide a conceptual clarification of four ideal types of research activities within this two-dimensional spectrum. Next, I shall provide an analysis of some of the various norms that drive research activities in different directions within the two-dimensional spectrum and the tensions that they may create.

\section{DISCIPLINARY AND INTERDISCIPLINARY DIVISION OF LABOR}

Scientists usually collaborate in order to do more or better work than they could have performed individually (Maienschein, 1993; Thagard, 2006; Wray, 2002). Collaborative activities therefore typically imply some epistemic dependence among collaborators. Collaborations may bring together scientists with similar contributory expertise or scientists with different kinds of contributory expertise. Both kinds of collaboration involve epistemic dependence, but they differ with respect to cognitive divergence or convergence.

In disciplinary divisions of labour, collaborative research activities that are cognitively convergent take place between scientists who all share much the same cognitive resources and therefore have highly similar contributory expertise, but who divide some amount of labor among them that it would be difficult for any one of the to overcome alone. Since it would be as time consuming for the individual participant of the collaborative activity to repeat the work of the others to establish the 
result for him- or herself instead of conferring to a collaborator, they will have to defer to each other for those partial contributions that result from the divided labor, and in this respect they are epistemically dependent. But at the same time, since they draw on highly similar cognitive resources, these individual contributions easily interlock, and hence only little additional interlocking expertise is required for the collaborators to interlock their individual contributions.

Conversely, collaborative research activities that are cognitively divergent will often take place between scientists who collaborate in order to combine cognitive resources that are distributed among them and which they do not all possess individually. ${ }^{8}$ But combining the contributions that they each provide based on their different contributory expertise requires that their individual contributions interlock. Since they derive from the application of divergent sets of cognitive resources, this requires additional interlocking expertise. Hence, this kind of interdisciplinary division of labour requires that sufficient interlocking expertise is also represented among the collaborators. The extent of the interlocking expertise required is related to the degree of interlocking of cognitive resources that is intended. Hence, for a high degree of integration of the various contributions, the required interlocking expertise is quite extensive. Conversely, if the various contributions merely need to be juxtaposed there may be less mutual dependence between collaborators and only need for interlocking expertise on some isolated points. ${ }^{9}$

\section{LEGENDS OF INDEPENDENCE IN DISCIPLINARY AND INTERDISCIPLINARY RESEARCH}

Epistemically independent researchers can be seen as autonomous epistemic agents who contribute to science-in-the-making individually rather than collaboratively. One type of non-collaborative activity is performed by epistemically independent scientists who work in a cognitively convergent area within which they each act as an autonomous epistemic agent. As argued above, however, this idea of fully epistemic independence is a chimera; in their research activities scientists will always be standing on the shoulders of their predecessors, historical as well as contemporary. Nevertheless, although this idea of scientists brought up in the same tradition to act as independent and autonomous

\footnotetext{
${ }^{8}$ Leonelli and Ankeny (2015) have recently introduced the term repertoires to denote the ensemble of material and social conditions that makes it possible for scientists to collaborate. Thus, repertoires include the collection of cognitive resources required for an interdisciplinary collaboration, but the analysis offered by Leonelli and Ankeny does not address the other dimension included in the account presented here, namely the importance of epistemic dependence among collaborators.

${ }^{9}$ By stressing the continuous character of the spectrum ranging from cognitive convergence and cognitive divergence as well as the fact that interlocking may happen at various degrees, this account does not lead to a strong division between inter- and multidisciplinarity as activities different in kind, but see them rather as differing in the degree of divergence and of interlocking.
} 
agents is a legend, it is at the same time a disciplinary legend on which previous models of the development of science have largely built.

For epistemically independent researchers working in a cognitively divergent area, there is a similar legend of scientists who have acquired full contributory expertise in all relevant domains and who are therefore capable of doing multi- or interdisciplinary research all alone as omniscient geniuses. Interlocking is still required between the various sets of cognitive resources, but while the fact that individual scientist has full contributory expertise in all domains involved eliminates the need for deference to the expertise of others, it does not eliminate the cognitive challenges of interlocking concepts, models or methods originally developed to describe different domains.

\section{EPISTEMIC VALUES, QuALITY CONTROL AND ACCOUNTABILITY}

Given the ideal types of research activities discussed above, I shall close by analyzing how different values may create tensions in contemporary science, first, between interdisciplinarity and quality control, and second, between collaboration and accountability, and I shall sketch how these tensions can be resolved.

As described above, scientists collaborate in groups in order to combine manpower, materials or other resources in an effort to produce new knowledge that they either could not have produced alone at all, or only at higher costs or with substantial delay. For example, research that is labor intensive can be performed at a higher speed by dividing work among collaborators. Similarly, research that is resource intensive can be performed more efficiency by sharing resources. Further, collaboration is epistemically beneficial because it enables knowledge to be developed and used by many people in many different fields, and that research in which more people direct their attention to the same puzzles tend to provide more desired results as well as better error detection (see e.g. Fallis, 2006; Thagard, 1997; 2006; Wray, 2002; 2006 for arguments of this type). Hence, several different values are involved in establishing collaborative activities as epistemically beneficial, including acquiring new knowledge as quickly and as cost-effective as possible, having new knowledge distributed as widely and as quickly as possible, and acquiring as much new knowledge as possible without introducing errors. ${ }^{10}$

\footnotetext{
${ }^{10}$ It may be a matter of dispute whether these values are seen as epistemic or non-epistemic. However, the overall argument of this paper does not depend on whether there is a clear distinction between epistemic and non-epistemic values.
} 
Similarly, scientists combine cognitive resources from different fields in order to solve problems that cannot be solved adequately within any of the involved fields alone. Combining cognitive resources from different fields in a new way can enable new solutions not imaginable within any of the individual fields, enable the creation of new, and from a disciplinary perspective very bold hypotheses, lead to a substantial expansion of the empirical content of the hypotheses advanced, and enable new conceptual combinations with the potential for establishing new theoretical frameworks. Hence, again several different values such as progress, ingenuity, and creativity are involved in establishing interdisciplinary activities as epistemically beneficial.

However, collaboration and interdisciplinarity are not only epistemically beneficial, they can also imply epistemic costs. For example, the benefit of being more people who can produce and disseminate more results needs to be balanced with the cost of the increased time required for communication and coordination. Similarly, the benefit of combining cognitive resources that enable new solutions to problems needs to be balanced with the cost that it makes the criteria of success less unequivocal and therefore more opaque. Hence, for most of the values described above, a balance needs to be found between costs and benefits. I shall here not attempt to derive a full epistemic value theory (see e.g. Goldman 1999 and Fallis 2006 for various versions of such a theory). Instead, I shall focus in the following on two particular topics that have been subject of intense discussion among scientists in recent years, namely accountability and quality control.

When collaborating, scientists divide labor among them. Doing so they repeatedly defer to each other and accept partial contributions by testimony from others rather than establishing each individual step in the research process themselves. This mutual deference runs counter to a strongly entrenched value in science, namely that of epistemic (or intellectual) autonomy. As described in detail by Fricker (2006), the ideal of the autonomous knowers who take no one else's work for anything but accept only what they have found out for themselves, relying purely on their own cognitive faculties and investigative and inferential powers, is an old and very strong ideal in philosophy.

Implicit in the idea of epistemic autonomy is also that, as autonomous knowers, scientists are individually responsible and accountable for the knowledge claims that they each advance. In contrast, when collaborators defer to each other for their partial contributions to the final result, accountability and responsibility cannot be ascribed to the individual in the same way. In research performed by groups rather than by individuals, accountability therefore appears to be challenged.11

\footnotetext{
${ }^{11}$ See e.g. (Rennie, 1994; Rennie, Yank, \& Emanuel, 1997; Task Force on Authorship, 2000; Nature editors, 2007) for expressions of this view.
} 
Further, also implicit in the idea of epistemic autonomy is that scientists always encounter the results obtained by others critically to reassure themselves of their correctness, rather than accepting them as testimony. But this requires that they are competent for the job. On the disciplinary legend described above, this competence follows naturally. According to the disciplinary legend, the practitioners within a discipline have undergone similar training and have absorbed the same literature and drawn the same lessons from it. As a consequence, they share the pursuit of the same goals, namely to solve problems that in characteristic ways resemble other problems that have been solved by the profession before. They are in principle each capable of pursuing the puzzles that their field defines. Further, when exchanging results, a scientist is capable of critically scrutinizing a new knowledge claim produced by a colleague before accepting it, and also of providing the justification for it if needed. This is the background for the argument that it is the critical scrutiny of results within the scientific community that makes normal science immensely efficient in identifying any loci of trouble. In contrast, when a research activity involves multiple disciplines, there is not a well-defined community of practitioners who are all expected to be equally capable of critically scrutinizing new results. In this situation, the quality control that on the disciplinary legend has been seen as resulting from the critical reception of new results in the community of equal peers is perceived as challenged.

Finally, these two concerns mutually enforce each other: the wider the cognitive divergence, the more need for epistemic dependence and the further the research activities move away from traditional ideals of individual accountability and community based quality control. In this way, there is an inherent tension in the development of contemporary science between, on the one hand, collaboration and accountability, and on the other hand between interdisciplinarity and quality control.

\section{COGNITIVE RESOURCES, INTERLOCKING AND QUALITY CONTROL}

The tension between interdisciplinarity and quality control has its root in the disciplinary legend's implicit premise that members of a particular scientific community are in principle each equally capable of producing and assessing a given result. However, as described in previous sections this is a chimera. Even scientists trained in the same domain through similar education will differ in their capacity for assessing a result produced by a peer, both because they may have subspecialized differently, and because they may differ in their intellectual capacity as such. Hence, even within monodisciplinary domains, quality control is a fragile process, and empirical work in sociology of science on peer review has long documented substantial disagreements among reviewers even within individual disciplines (see e.g. Cole, Cole, \& Simon, 1981). For interdisciplinary research, problems intensify because the individual assessor is usually not in command of all cognitive resources involved and is in this sense epistemically inferior to the group which produced it. This inability of referees to assess all aspects of an interdisciplinary piece of work epistemic has been a recurrent topic in 
discussion of peer review in interdisciplinary research (see e.g. Porter \& Rossini, 1985; Mansilla, Feller, \& Gardner, 2006; Mansilla, 2006; Langfeldt, 2006).12 Proponents of interdisciplinarity have maintained that knowledge assessors do not appreciate what is achieved by interlocking various cognitive resources, vice versa, critics of interdisciplinarity have maintained that knowledge assessors are incapable of identifying shortcomings outside their own area of expertise. ${ }^{13}$

To meet this criticism, the implications of an epistemic inequality between knowledge producer and knowledge assessor need to be addressed. Importantly, this inequality concerns not only the cognitive resources covered, but also their interlocking. Whereas coverage of relevant cognitive resources is achieved by most assessment models, there is much variation with respect to interlocking and epistemic dependence. Thus, a model in which multiple scientists with different contributory expertise provide individual reviews to a given piece of work (practiced, for example, by interdisciplinary journals like Behavioural and Brain Science), easily covers all relevant cognitive resources, but there may be little, if any, interlocking of these into a synthesized assessment. Such a model may work well for examining the quality of each disciplinary aspect, but at the same time have difficulties recognizing the benefits gained from the interdisciplinary interlocking. A central 'synthesizer' may therefore be added who integrates all assessments into one, as it is often done by a journal editor. However, for this to produce a satisfactory result the synthesizer needs sufficient expertise to provide the same degree of interlocking as the knowledge producing group. Such omniscience is rare, and this model may therefore also have difficulties recognizing benefits gained from interdisciplinary interlocking. A third model is therefore to bring multiple experts together as a panel and in this group merge their individual assessments, similar to the interlocking of contributions in the knowledge producing group. Several empirical studies of peer review of interdisciplinary research proposals suggest that, given sufficient interaction between panel members, transparent distribution of labor, an adequate balance of perspectives, and open discussion of different standards, this is a viable model (Mansilla et al., 2006; Mansilla, 2006; Langfeldt, 2006; Huutoniemi, 2010; Huutoniemi, 2012). ${ }^{14}$ At the same time, such a

\footnotetext{
${ }^{12}$ It should be noted that much of this literature has addressed funding decisions about future research rather than quality decisions about performed research. Obviously, the former includes additional challenges due to the inherently more uncertain character of the decision, cf. Porter \& Rossini (1985)

${ }^{13}$ Part of this criticism is raised implicitly rather than explicitly in printed documents. However, a widespread 'unease' about the 'dubious quality' of interdisciplinary research has been reported in many publications on quality control and on interdisciplinarity (see e.g. Feller, 2006; Mansilla et al., 2006; Weingart, 2000).

${ }^{14}$ More recently, research in peer review has started to address groupthink and similar the undesired phenomena that may occur in group judgements (Olbrechts \& Bornmann, 2010). Similar considerations are also seen in the social epistemology literature on decision making in groups (Solomon, 2006). However, the possible
} 
model is labor intensive, and while grant agencies may bring panels together physically for major funding decisions, panel models are rare - if at all possible - for the vast multitude of interdisciplinary journal papers that are continuously submitted for peer review.

However, what has been largely overlooked in the debate about quality control in interdisciplinary research is how standard peer review practices developed from the interdisciplinary legend's focus on the individual scientist deviates from contemporary practices oriented rather towards interdisciplinary collaboration. Thus, while most interdisciplinary research is now produced by groups, peer review of reports of the performed research, even in highly interdisciplinary fields, is still largely performed by individuals. Hence, most journals send manuscripts to individual scientist, stressing that they are not allowed to involve anyone else in the review of the manuscript (see, for example, the COPE Ethical Guidelines for Peer Reviewers issued by the Committee on Publication Ethics, publicationethics.org). Instead, in order to restore the epistemic equality between knowledge producer and knowledge assessor a more suitable practice would be to request reviews explicitly from groups that are similar to the knowledge producing group, i.e. groups working on similar problems and spanning similar areas of expertise. Hence, while most current journal guidelines stress that, for example, junior collaborators may only be involved in the review process after explicit permission by the editor, thereby signaling that such collaborative reviews are the exception rather than the rule, this suggestion turns the standards upside-down and requires that collaborators are involved. On such a model, knowledge producer and knowledge assessor would be tokens of the same type, not only in drawing on the same multitude of cognitive resources, but also by ensuring that the synthesis of disciplinary viewpoints is conducting similarly during knowledge production and knowledge assessment.

\section{EPISTEMIC AUTONOMY, DEPENDENCE AND ACCOUNTABILITY}

In resolving the tension between collaboration and accountability it is important to note that, as argued earlier in this paper, the idea of epistemic autonomy is largely a chimera that sets up an unrealistic ideal for accountability. Similar arguments about epistemic autonomy being unrealistic in general has been made by Fricker (2006), who points out that this ideal holds only for an infinite, superior being, otherwise the epistemic autonome will be severely cognitively lacking, and by Coady (2002) who redescribes the autonomous knower as the autonomous ignoramus. Second, accountability appears to be challenged because it cannot be unequivocally ascribed to a single individual, but that does not mean that it cannot be distributed among collaborators in a group or

dangers of groupthink and similar phenomena lie outside the scope of this paper. 
ascribed to the group as a plural subject. Hence, as I shall argue in the following, accountability in collaborative research can be restored by making its distribution among group members transparent.

As argued by Hardwig (1985; 1991), in order for a scientist to trust a claim made by a collaborator, the collaborator's reasons for this claim must be better than the reasons that the scientist can come up with alone. The scientist must therefore have reasons to believe that the collaborator is competent and knows what would be good reasons for the claim, has worked conscientiously and actually has these good reasons, and speaks truthfully in advancing the claim. In other words, trust is based on the trustee having good reasons for believing in the epistemic and moral character of the collaborator whose claim is being trusted. These good reasons form part of the scientist's total warrant for believing the claim in question. However, in contrast to first-order warrants for believing a scientific claim, such as observation reports, theoretical inferences etc. that are usually presented explicitly, second order warrants for a believing a scientific claim - i.e. the reasons for adopting another scientist's testimony as reasons for believing the claim - are rarely explicated at all and therefore remain largely opaque.

It is largely due to this opaqueness of trust together with an unrealistic ideal of the individual's epistemic autonomy that the accountability of collaborative science has been questioned. Hence, to restore accountability in collaborative research the role of trust needs be made transparent. First, the distribution of direct accountability for partial contributions among individual collaborators can be made transparent. This step has been taken recently by several science journals, including, for example, all journals from the Nature group which since 2009 has required that articles contain a contribution statement that specifies the contribution of every author.

Second, collaborators need to consider their warrant for believing in the epistemic and moral character of each of their collaborators. An initial move in this direction can be found in the so-called Vancouver Guidelines, a set of recommendations on journal publication issued by the International Committee of Medical Journal Editors (ICMJE). Since 2013 these guidelines have specified that "authors should have confidence in the integrity of the contributions of their co-authors" (ICMJE, 2014, p. 2). ${ }^{15}$ To assess whether a collaborator is competent in a given field requires that the assessor is at

\footnotetext{
${ }^{15}$ While the Vancouver Guidelines only specify that authors should have confidence in the integrity of their collaborators, in Hardwig's term their moral character, the press release issued by the ICMJE at the release of the 2013 modification of the Vancouver Guidelines goes a step further and specifies that authors should have confidence in co-authors' integrity and ability, thus including also their epistemic character. However, this has not yet moved into the official recommendation document. Further, both documents have remained silent on how confidence in collaborators' moral and epistemic character should be established.
} 
least as competent. Hence, calibration of trust is dependent of the difference in epistemic status between collaborators. Ascribing responsibility for a group's result therefore needs adjustments between, for example, juniors and seniors, or between scientists with different areas of expertise. That there is such a difference has also been the intuition of several investigation committees examining cases of scientific misconduct (see e.g. Andersen, 2014 for details). Yet, rather than claritying how trust is calibrated, given different levels of seniority and expertise, there is a tendency instead to take recourse to control in an attempt to avoid trust altogether. For example, biomedical editors have proposed that for all co-authored papers, a senior PI should be assigned a special function as the 'guarantor' who vouches for the integrity of the work in its entirety (Rennie et al., 1997). But this proposal simply recreates the disciplinary legend's ideal of an individual autonomous knower, even in a collaborative setting where it makes little sense. Instead, what is needed is to make much more explicit the practices by which scientists actually do assess each other. Seniors' assessments of juniors' epistemic character is obviously an integral and explicit part of training programs. But seniors also assess their peers, including peers from different fields, by standards such as dialoguing practices or explanatory responsiveness (Wagenknecht, 2014). Similarly, various standards can be described that are important in the assessment of moral character, such as honesty, loyalty, cooperativeness, fairness, or consideration for others (Frost-Arnold, 2013). Hence, although the relations of epistemic dependence implies that accountability in collaborative research is both distributed and graded, this does not imply that it needs to remain opaque.

\section{REVISITING THE STRUCTURE OF SCIENCE}

Most philosophical analyses from the $20^{\text {th }}$ century on the development of science were analyses of the development of individual scientific disciplines, usually described in terms of the development of their paradigms, research programs or research traditions. ${ }^{16}$ While collaboration and interdisciplinarity are far from new phenomena, for the historically-oriented, developmental accounts that developed in the 1960es and 1970es by Kuhn and others, focus was still predominantly on disciplines as they had developed over the preceding two centuries to become the defining structure of the scientific enterprise that was expanding rapidly during the postwar era when the accounts were developed. Further, investigating how science developed over time, a turn to history seemed a natural move, and hence cases illustrating the accounts were often drawn from previous centuries and showed how individual scientists contributed to the disciplinary tradition, whether by expanding or changing it.

\footnotetext{
${ }^{16}$ Laudan's brief reflection on the possibility of grafting or amalgamating research traditions (Laudan, 1977, pp. 103-105) as well as Fleck's (1980) early idea of individual scientists' simultaneous membership of multiple thought collectives serve as the two main exceptions. However, neither of these ideas has been substantially explored as analyses of interdisciplinary science.
} 
During the half century that has passed since the publication of Kuhn's Structure and the work of the philosophers he inspired, collaborative and interdisciplinary practices have come to play significant roles for the scientific enterprise. Time is therefore ripe for revisiting and rethinking philosophical analyses of the structure of science and its development.

Such an undertaking necessarily goes beyond the scope an individual paper. However, what this paper has shown is, first, that the degree of cognitive convergence and divergence as well as the degree of epistemic dependence among collaborators are key dimensions for understanding the structure of contemporary science, second, that an analysis in terms of these dimensions not only reveals where our understanding of science may be influenced by untenable ideas, but also how to revise our understanding of such important aspects of scientific practice as accountability and quality control.

Acknowledgements: Previous versions of this paper were presented at the conferences Challenging Philosophy: Interdisciplinary problems and disciplinary philosophy (Tübingen 2012), GTCP (Amsterdam 2014), and PSA (Chicago 2014), and I would like to thank the audiences for valuable feedback. I would also like to thank members of my research group Philosophy of Contemporary Science in Practice as well as two anonymous referees for valuable comments to earlier versions of this paper. Finally, I would like to thank the Danish Research Council for Independent Research I Humanities for financial support of this research, and the Department of Philosophy at Universität Konstanz as well as the Innovationszentrum Wissensforschung at the TU Berlin for their hospitality while writing the final manuscript.

Reference List

Abbott, A. (2001). The Chaos of Disciplines. Chicago: University of Chicago Press.

Andersen, H. (2014). Co-author responsibility. Distinguishing between the moral and epistemic aspects of trust. EMBO reports, 15, 915-918.

Andersen, H. \& Wagenknecht, S. (2013). Epistemic dependence in interdisciplinary groups. Synthese, 190, 1881-1898.

Andersen, H. (2000). Learning by Ostension: Thomas Kuhn on Science Education. Science \& Education, 9, 91-106.

Braun, T. \& Schubert, A. (2003). A quantitative view on the coming of age of interdisciplinarity in the sciences 1980-1999. Scientometrics, 58, 183-189.

Coady, C. A. J. (2002). Testimony and intellectual autonomy. Studies in History and Philosophy of Science, 33, 355-372.

Cole, S., Cole, J. R., \& Simon, G. A. (1981). Chance and consensus in peer review. Science, 214, 881-886.

Collins, H. M. \& Evans, R. (2002). The Third Wave of Science Studies: Studies of Expertise and Experience. Social Studies of Science, 32, 235-296.

Crane, D. (1969). Social Structure in a Group of Scientists: A Test of the 'Invisble College' Hypothesis. American Sociological Reveiw, 34, 335-352.

Etzkowitz, H. (2008). The Triple Helix. University-Industry-Government Innovation in Action. London: Routledge.

Etzkowitz, H. \& Leydesdorff, L. (2000). The dynamics of innovation: From National Systems and "Mode 2" to a Triple Helix of university-industry-government relations. Research Policy, 29, 109-123.

Fallis, D. (2006). The Epistemic Costs and Benefits of Collaboration. Southern Journal of Philosophy, XLIV, 197-208. 
Feller, I. (2006). Multiple actors, multiple settings,multiple criteria: issues in assessing interdisciplinary research. Research Evaluation, 15, 5-15.

Fleck, L. (1980). Entstehung und Entwicklung einer wissenschaftlicher Tatsache. Frankfurt: suhrkamp.

Fricker, E. (2006). Testimony and epistemic authonomy. In J.Lackey \& E. Sosa (Eds.), The epistemology of testimony (pp. 225245). Oxford: Oxford University Press.

Frost-Arnold, K. (2013). Moral trust \& scientific collaboration. Studies in History and Philosophy of Science, 44, 301-310.

Funtowicz, S. \& Ravetz, J. (1993). The emergence of post-normal science. In R.Schomberg (Ed.), Science, politics and morality (pp. 85-123). Dordrecht: Springer.

Funtowicz, S. \& Ravetz, J. (1995). Science for the post-normal age. In L.Westra \& J. Lemons (Eds.), Perspectives in ecological integrity (pp. 146-161). Dordrecht: Kluwer.

Galison, P. (1997). Image and Logic. A Material Culture of Microphysics. Chicago: University of Chicago Press.

Genuth, J., Chompalov, I., \& Shrum, W. (2000). How experiments begin: The formation of scientific collaborations. Minerva, 38, 311-348.

Gibbons, M., Limoges, C., Nowotny, H., Schwarzman, S., Scott, P., \& Trow, M. (1994). The new production of knowledge. The dynamics of science and research in contemporary societies. London: SAGE.

Goddiksen, M. P. (2014). Clarifiying interactional and contributory expertise. Studies in History and Philosophy of Science.Part $A, 47,111-117$.

Goldberg, S. (2011). The division of epistemic labor. Episteme, 8, 112-125.

Hackett, E. J. (2005). Essential Tensions: Identity, Control, and Risk in Research. Social Studies of Science, 35, 826.

Hagstrom, W. O. (1965). The Scientific Community. New York.

Huutoniemi, K. (2010). Evaluating interdisciplinary research. In R.Frodeman, J. T. Klein, \& C. Mitcham (Eds.), The Oxford Handbook of Interdisciplinarity (pp. 309-320). Oxford: Oxford University Press.

Huutoniemi, K. (2012). Communicating and compromising on disciplinary expertise in the peer review of research proposals. Social Studies of Science, 42, 897-921.

ICMJE. (2014). Recommendations for the conduct, reporting, editing, and publication of scholarly work in medical journals.

Ref Type: Online Source

Kuhn, T. S. (1970). The Structure of Scientific Revolutions. Chicago: Chicago University Press.

Lakatos, I. (1971). History of science and its rational reconstructions. Boston Studies in the Philosophy of Science, VIII, 91-136.

Langfeldt, L. (2006). The policy challenges of peer review: managing bias, conflict of interests and interdisciplinary assessments. Research Evaluation, 15, 31-41.

Laudan, L. (1977). Progress and Its Problems. Towards a Theory of Scientific Growth. Berkeley: University of California Press.

Lee, S. \& Bozeman, B. (2012). The Impact of Research Collaboration on Scientific Productivity. Social Studies of Science, 35, 673-702.

Leonelli, S. \& Ankeny, R. A. (2015). Repertoires: How to Transform a Project into a Research Community. BioScience.

Maienschein, J. (1993). Why Collaborate? Journal of the History of Biology, 26, 167-183.

Mansilla, V. B. (2006). Assessing expert interdisciplinary work at the frontier: an empirical exploration. Research Evaluation, $15,17-29$.

Mansilla, V. B., Feller, I., \& Gardner, H. (2006). Quality assessment in interdisciplinary research and education. Research Evaluation, 15, 69-74.

Nature editors (2007). Accountability of authors. Nature, 450, 1.

Nowotny, H., Scott, P., \& Gibbons, M. (2001). Re-Thinking Science. Knowledge and the Public in an Age of Uncertainty. Cambridge: Polity Press.

Olbrechts, M. \& Bornmann, L. (2010). Panel peer review of grant applications: what do we know from research in social psychology on judgment and decision-making in groups? Research Evaluation, 19, 293-304.

Parker, J. N. \& Hackett, E. J. (20201). Hot spots and hot moments in scientific collaborations and social movements. Americal Sociological Review, 77, 21-44.

Petrie, H. G. (1976). Do You See What I See? The Epistemology of Interdisciplinary Inquiry. Educational Researcher, 5, 9-15.

Plaisance, K. S. \& Kennedy, E. B. (2014). Interactional expertise: A pluralistic approach. Studies in History and Philosophy of Science.Part A, 47, 60-68.

Porter, A. L. \& Rafols, I. (2009). Is science becoming more interdisciplinary? Measuring and mapping six research fields over time. Scientometrics, 81, 719-745.

Porter, A. L. \& Rossini, F. A. (1985). Peer review of interdisciplinary research proposals. Science, Technology \& Human Values, $10,33-38$.

Price, D. J. d. S. \& Beaver, D. d. B. (1966). Collaboration in an Invisible College. American psychologist, 21, 1011-1018.

Rennie, D. (1994). Authorship! Authorship! Guest, Ghosts, Grafters, and the Two-Sided Coin. JAMA, 271, 469-471.

Rennie, D., Yank, V., \& Emanuel, L. (1997). When Authorship Fails: A Proposal to Make Contributors Accountable. JAMA, 278, 579-585.

Shapere, D. (1977). Scientific theories and their domains. In F.Suppe (Ed.), The Structure of Scientific Theories (pp. 518-589). University of Illinois Press.

Shrum, M. S., Chompalov, I., \& Genuth, J. (2001). Trust, Conflict, and Performance in Scientific Collaborations. Social Studies of Science, 31, 681-730.

Shrum, W., Genuth, J., \& Chompalov, I. (2007). Structures of Scientific Collaboration. Cambridge MA: MIT Press. 
Solomon, M. (2006). Groupthink versus The Wisdom of Crowds: The Social Epistemology of Deliberation and Dissent. The Southern Journal of Philosophy, 44, 28-42.

Stichweh, R. (1992). The Sociology of Scientific Disciplines: On the Genesis and Stability of the Disciplinary Structure of Modern Science. Science in Context, 5, 3-15.

Task Force on Authorship (2000). Who's the Author? Problems with Biomedical Authorship, and Some Possible Solutions. Science Editor, 23, 111-119.

Thagard, P. (1997). Collaborative Knowledge. Nous, 31, 242-261.

Thagard, P. (2006). How to Collaborate: Procedural Knowledge in the Cooperative Development of Science. Southern Journal of Philosophy, XLIV, 177-196.

Wagenknecht, S. (2014). Facing the incompleteness of epistemic trust- managing dependence in scientific practice. Social Epistemology.

Weingart, P. (2000). Interdisciplinarity: The Paradoxical Discourse. In P.Weingart \& N. Stehr (Eds.), Practicing Interdisciplinarity (pp. 25-42). Toronto: University of Toronto Press.

Weingart, P. (2010). A short history of knowledge formation. In R.Frodeman, J. Klein, \& C. Mitcham (Eds.), The Oxford Handbook of Interdisciplinarity (pp. 3-14).

Wray, K. B. (2002). The Epistemic Significance of Collaborative Research. Philosophy of Science, 69, 150-168.

Wray, K. B. (2006). Scientific authorship in the age of collaborative research. Studies in History and Philosophy of Science.

Wuchty, S., Jones, B. F., \& Uzzi, B. (2007). The Increasing Dominance of Teams in Production of Knowledge. Science, 316, 10361039. 